\title{
Mathematical Modeling of Temperature Field of Multilayer Enclosure Structures
}

\author{
Boris Aksenov ${ }^{1, *}$, Svetlana Karyakina ${ }^{1}$, Oleg Stepanov ${ }^{1}$, Anatoly Shapoval ${ }^{1}$, and Mikhail \\ Bodrov $^{2}$ \\ ${ }^{1}$ Industrial University of Tyumen, 625001 Volodarskogo str. 38, Tyumen, Russia \\ ${ }^{2}$ Nizhny Novgorod State University of Architecture and Civil Engineering, 603950 Ilyinskaya str. 65, \\ Nizhny Novgorod, Russia
}

\begin{abstract}
The mathematical model of heat exchange process through multilayer enclosure structure is constructed. Herein infiltration and heatconducting inclusions are taken into account. Heat exchange process modeling in the stationary and non- stationary conditions is considered.The method of temperature field constructing based on the suggested model is offered. The three-dimensional boundary problem of non- stationary heat conductivity is solved numerically using the implicit method of alternating directions. The temperature field constructing of the enclosure structures in the non- stationary condition allows to track dynamics of thermal flows through enclosing structures and to receive the thermal resistance considering influence of heat-conducting inclusions.
\end{abstract}

\section{Introduction}

There are problems with indoor microclimate when using the thermally insulated cladding panel with aluminum alloy skin.

Modeling of heat exchange processes in the panel is required to work out the premises design with the required positive temperature indoors at a negative external air temperature. Moreover the inside temperature differentials should not exceed the set norms.

Work [1] offers the heat exchange model in aluminum panels at the following assumptions: stationary condition of the process, constancy of thermophysical properties of materials, independence of heat exchange process on mass transfer. This model represents a system of equations describing heat exchange on cladding panel internal and external skins and through panel joints.

It is possible to calculate temperature distribution on the panel skin by a twodimensional boundary problem of stationary heat conductivity.

The stationary model is insufficient for accurate thermal structural calculations when operating the factory-assembled buildings in environments with large diurnal temperature variation and strong winds. During the time required to establish stationary state both the outside air temperature and the indoor heat balance may change.

\footnotetext{
* Corresponding author: tgasu.aksenov.boris@,mail.ru
} 


\section{Modeling of heat exchange processes in the enclosure structures in non-stationary conditions}

The physical and mathematical model is based on the following assumptions. Heat is transferred from indoor air to the inner skin plate, then through the insulation layer to the outer siding and then into the atmosphere. Besides there is a heat flow through the "thermal bridge" having a high thermal conductivity. It should be noted that the standard panel thickness is an order less than its height and length.

Thermophysical properties of materials are represented by functions depending on time and coordinates. Mass transfer is not taken into account.

The temperature distribution on internal and external panel skin surface is characterized by heat exchange at a panel skin surface. The equations describing the distribution of temperature on an internal and external panel skin surface are derived from the equation of thermal balance, and contain heat and moisture exchange coefficients which are defined by the intensity of a convective heat transfer, radiation heat exchange of internal and external enclosure structure surfaces.

Temperature on a side plate is not calculated. Heat exchange through panel joints is taken into account when formulating boundary conditions. The thermal flow arriving to a joint along the plate consists of the heat loss flow through heat-conducting inclusion from the premises into environment, and the cold air infiltration flow heating conditioned by more preheated panel.

The thermal flow in a thermal insulation layer is considered directed strictly perpendicular to the panel plane as near the panel edge the flow through insulation is small enough in comparison with the flow through a metal panel skin.

Let us introduce a three-dimensional Cartesian coordinate system with the origin at the center of the internal panel skin size $2 a \times 2 b \times d$. The direction of the axis $Z$ from the inner panel skin to the outer one is then $-a \leq x \leq a,-b \leq y \leq b, 0 \leq z \leq d$.

To derive the equation describing the temperature distribution $t_{1}$ on the inner panel skin surface, let us consider the surface element $d x \times d y \times \delta$, where $\delta$ is the panel skin thickness.

Let us express the heat flowing into surface element along the axes $\mathrm{X}, \mathrm{Y}, \mathrm{Z}$ respectively at time $\tau$ by $Q_{x}(\tau, x, y) Q_{y}(\tau, x, y) Q_{z}(\tau, x, y, z)$. Based on Fourier's law mathematical expression of these flows is as follows:

$$
\begin{aligned}
& Q_{x}(\tau, x, y)=-\lambda_{a} \cdot \delta \cdot d y \frac{\partial t_{1}(\tau, x, y)}{\partial x} \cdot d \tau \\
& Q_{y}(\tau, x, y)=-\lambda_{a} \cdot \delta \cdot d x \frac{\partial t_{1}(\tau, x, y)}{\partial y} \cdot d \tau, \\
& \left.Q_{z}(\tau, x, y, z)\right|_{z=0}=\alpha_{1}\left(t_{w}(\tau)-t_{1}(\tau, x, y, z)\right) d x \cdot d y \cdot d \tau
\end{aligned}
$$

The expressions for the resulting heat flow can be written as follows: 


$$
\begin{aligned}
& Q_{x}(\tau, x+\Delta x, y)=-\lambda_{a} \cdot \delta \cdot d y \frac{\partial t_{1}(\tau, x+\Delta x, y)}{\partial x} \cdot d \tau \\
& Q_{y}(\tau, x, y+\Delta y)=-\lambda_{a} \cdot \delta \cdot d x \frac{\partial t_{1}(\tau, x, y+\Delta y)}{\partial y} \cdot d \tau \\
& \left.Q_{z}(\tau, x, y, z)\right|_{z=\delta}=-\left.\lambda_{s} \cdot d x \cdot d y \frac{\partial t_{s}(\tau, x, y, z)}{\partial z}\right|_{z=\delta} \cdot d \tau .
\end{aligned}
$$

where $\lambda_{a}, \lambda_{s}$ are panel skin and insulation thermal conductivity, $\alpha_{1}$ is heat exchange coefficient on an internal panel skin, $t_{s}$ is isolation temperature; $t_{w}$ is average air temperature indoors.

In the non-stationary condition the heat balance equation is:

$$
\begin{aligned}
& \left(Q_{x}(\tau, x, y)+Q_{y}(\tau, x, y)+\left.Q_{z}(\tau, x, y, z)\right|_{z=0}\right)- \\
& -\left(Q_{x}(\tau, x+\Delta x, y)+Q_{y}(\tau, x, y+\Delta y)+\left.Q_{z}(\tau, x, y, z)\right|_{z=\delta}\right)=d H,
\end{aligned}
$$

where $d H$ is the enthalpy change of the panel skin element

$$
d H=c_{a} \frac{\partial t_{1}(\tau, x, y, z)}{\partial \tau} \cdot d \tau \cdot d V
$$

where $c_{a}$ is thermal capacity of panel skin unit volume, $d V$ - panel skin element volume

After rearrangement the thermal balance equation (3) with regard to (1), (2), (4) will change to:

$$
\begin{aligned}
& \lambda_{a}\left(\frac{\partial^{2} t_{1}(\tau, x, y)}{\partial x^{2}}+\frac{\partial^{2} t_{1}(\tau, x, y)}{\partial y^{2}}\right)+\left.\frac{\lambda_{s}}{\delta} \frac{\partial t_{s}(\tau, x, y, z)}{\partial z}\right|_{z=\delta}+ \\
& +\frac{\alpha_{1}}{\delta}\left(t_{w}(\tau)-t_{1}(\tau, x, y)\right)=c_{a} \frac{\partial t_{1}(\tau, x, y)}{\partial \tau}, \\
& -\alpha<x<a,-b<y<b,
\end{aligned}
$$

The equation describing thermal balance for the panel external surface is derived similarly and has a form:

$$
\begin{aligned}
& \lambda_{a}\left(\frac{\partial^{2} t_{2}(\tau, x, y)}{\partial x^{2}}+\frac{\partial^{2} t_{2}(\tau, x, y)}{\partial y^{2}}\right)-\left.\frac{\lambda_{s}}{\delta} \frac{\partial t_{s}(\tau, x, y, z)}{\partial z}\right|_{z=d-\delta}+ \\
& +\frac{\alpha_{2}}{\delta}\left(t_{u}(\tau)-t_{2}(\tau, x, y)\right)=c_{a} \frac{\partial t_{2}(\tau, x, y)}{\partial \tau} \\
& -a<x<a,-b<y<b
\end{aligned}
$$


where $t_{2}$ is external panel skin temperature, $t_{u}$ is the average air temperature outdoors, $\alpha_{2}$ is heat exchange coefficient on an external panel skin.

For the insulation layer the heat flows only in the direction $\mathrm{Z}$ according to the accepted assumptions. $Q_{x}=Q_{y}=0$ is considered. Let us consider the balance of heat flows for an insulation element $d x \times d y \times d z$.

The inward flow

$$
Q_{z}(\tau, x, y, z)=-\lambda_{s} \cdot d x \cdot d y \cdot \frac{\partial t_{s}(\tau, x, y, z)}{\partial z} \cdot d \tau
$$

where $t_{s}$ is temperature insulation, $\lambda_{s}$ is thermal conductivity of the insulation material. The outward flow

$$
Q_{z}(\tau, x, y, z+\Delta z)=-\lambda_{s} \cdot d x \cdot d y \cdot \frac{\partial t_{s}(\tau, x, y, z+\Delta z)}{\partial z} \cdot d \tau
$$

The equation of thermal balance is:

$$
\lambda_{s} \cdot d x \cdot d y \cdot d \tau\left(\frac{\partial t_{s}(\tau, x, y, z+\Delta z)}{\partial z}-\frac{\partial t_{s}(\tau, x, y, z)}{\partial z}\right)=c_{s} \cdot \frac{\partial t_{s}(\tau, x, y, z)}{\partial \tau} \cdot d \tau \cdot d V
$$

where $c_{s}$ is heat capacity of insulation material unit volume, $d V$ is the insulation unit volume.

After the rearrangement (9) will take a form:

$$
\begin{aligned}
& \frac{\lambda_{s}}{c_{s}} \frac{\partial^{2} t_{s}(\tau, x, y, z)}{\partial z^{2}}=\frac{\partial t_{s}(\tau, x, y, z)}{\partial \tau}, \\
& -a<x<a,-b<y<b, \delta \leq z \leq d-\delta .
\end{aligned}
$$

Boundary conditions are set similarly [1]:

$x=-a$ :

$\frac{\partial t_{1}(\tau, x, y)}{\partial x}=-\frac{\partial t_{2}(\tau, x, y)}{\partial x}=$

$\frac{\left(t_{1}(\tau, x, y)-t_{2}(\tau, x, y)\right)}{l_{2}}+\frac{M C_{\mathrm{p}}\left(t,(\tau)-t_{c w}(\tau, x, y)\right)}{\delta \lambda_{a}}$.

$x=+a$ :

$-\frac{\partial t_{1}(\tau, x, y)}{\partial x}=\frac{\partial t_{2}(\tau, x, y)}{\partial x}=$

$\frac{\left(t_{1}(\tau, x, y)-t_{2}(\tau, x, y)\right)}{l_{1}}+\frac{M C_{\mathrm{p}}\left(t,(\tau)-t_{c w}(\tau, x, y)\right)}{\delta \lambda_{a}}$. 


$$
\begin{aligned}
& y=-b: \\
& \frac{\partial t_{1}(\tau, x, y)}{\partial y}=-\frac{\partial t_{2}(\tau, x, y)}{\partial y}= \\
& \frac{\left(t_{1}(\tau, x, y)-t_{2}(\tau, x, y)\right)}{l_{4}}+\frac{M C_{\mathrm{p}}\left(t,(\tau)-t_{c w}(\tau, x, y)\right)}{\delta \lambda_{a}} . \\
& y=+b: \\
& -\frac{\partial t_{1}(\tau, x, y)}{\partial y}=\frac{\partial t_{2}(\tau, x, y)}{\partial y}= \\
& \frac{\left(t_{1}(\tau, x, y)-t_{2}(\tau, x, y)\right)}{l_{3}}+\frac{M C_{\mathrm{p}}\left(t,(\tau)-t_{c w}(\tau, x, y)\right)}{\delta \lambda_{a}} .
\end{aligned}
$$

where $l_{1}, l_{2}, l_{3}, l_{4}$ are length dimension parameters characterizing heat-conducting inclusions, $M$ is the discharge of infiltrating air per unit length per second, $t_{c w}$ is temperature of the cold air coming inside through a joint; $C_{p}$ is specific air heat capacity.

The left part of boundary conditions characterizes a heat flow due to heat conductivity of a panel skin, the right one is proportional to a temperatures difference of external and internal part of a joint.

It is advisable to accept

$$
t_{s}(\tau, x, y, \delta)=t_{1}(\tau, x, y), \quad t_{s}(\tau, x, y, d-\delta)=t_{2}(\tau, x, y)
$$

Initial conditions:

$$
\begin{aligned}
& t_{1}(0, x, y)=t_{w}(0), \\
& t_{2}(0, x, y)=t_{u}(0), \\
& t_{s}(0, x, y, z)=t_{w}(0)-z \cdot \frac{t_{w}(0)-t_{u}(0)}{d}, \\
& -a \leq x \leq a, \quad-b \leq y \leq b, \quad \delta \leq z \leq d-\delta .
\end{aligned}
$$

The simultaneous solution of (5), (6), (10), (11) - (16) are used to construct the temperature field of the panel.

Numerical solution of the boundary value problem of non-steady heat conduction

For the numerical solution of the problem (5), (6), (10), (11) - (16) we use the implicit method of alternating directions. We introduce the grid

$$
\omega_{h \tau}=\omega_{h} \times \omega_{\tau}=\left\{\begin{array}{l}
\left(i_{1} h_{1}, i_{2} h_{2}, i_{3} h_{3}, j \Delta \tau\right), \\
i_{1}=0,1, \ldots, N_{1}, i_{2}=0,1, \ldots, N_{2} \\
i_{3}=0,1, \ldots, N_{3}, j=0,1, \ldots, N_{\tau}
\end{array}\right\}
$$


With grid steps $h_{1}=\frac{2 a}{N_{1}}, \quad h_{2}=\frac{2 b}{N_{2}}, \quad h_{3}=\frac{d}{N_{3}}, \quad \Delta \tau=\frac{T}{N_{\tau}}$.

For the equation of an internal panel skin we receive two boundary problems. The index $i_{3}$ is omitted, since we get $i_{3}=0$ for points of the inner panel skin.

The first problem is

$$
\begin{aligned}
& 0,5 \beta_{1} t_{1 i_{1}-1, i_{2}}^{j+1 / 2}-k_{1} t_{1} t_{i_{1}, i_{2}}^{j+1 / 2}+0,5 \beta_{2} t_{1} t_{i_{1}+1, i_{2}}^{j+1 / 2}=-F_{i_{1}, i_{2}}^{j+1 / 2}, i_{1}=1,2, \ldots, N_{1}-1\left(0<i_{2}<N_{2}\right), \\
& \beta_{1}=\frac{\lambda_{a} \Delta \tau}{c_{a}\left(h_{1}\right)^{2}}, \beta_{2}=\frac{\lambda a}{c_{a}\left(h_{2}\right)^{2}}, k_{1}=1+\beta_{1}-\frac{\Delta \tau}{2 \delta c_{a}}\left(\alpha_{1}+\frac{\lambda_{s}}{h_{3}}\right), \\
& F_{i_{1}, i_{2}}^{j+1 / 2}=0,2 \beta_{2}\left(t_{1_{i_{1}, i_{2}-1}^{j}}^{j}+t_{1}^{j} i_{i_{1}, i_{2}+1}\right)+\left(1-\beta_{2}\right) t_{1 i_{1}, i_{2}}^{j}-\frac{\lambda_{a} \Delta \tau}{2 c_{a}} f^{j+1 / 2}, \\
& f^{j+1 / 2}=\left(\frac{\lambda_{s}}{\lambda_{a} \delta h_{3}} t_{s i_{1}, i_{2}}^{j}+\frac{\alpha_{1}}{\lambda_{a} \delta} t_{w}(\Delta \tau(j+0,5)) .\right.
\end{aligned}
$$

The boundary conditions are:

$$
\begin{aligned}
& t_{10, i_{2}}^{j+1 / 2}=t_{11, i_{2}}^{j+1 / 2}+h_{1}\left(\frac{\left(t_{10, i_{2}}^{j}-t_{20, i_{2}}^{j}\right)}{l_{2}}+L\right), \\
& t_{1 N_{1}, i_{2}}^{j+1 / 2}=t_{1 N_{1}-1, i_{2}}^{j+1 / 2}+h_{1}\left(\frac{\left(t_{2 N_{1}, i_{2}}^{j}-t_{1 N_{1}, i_{2}}^{j}\right)}{l_{1}}+L\right), \\
& \text { where } L=\frac{M C_{p}\left(t_{\mathrm{u}}{ }^{j}-t_{\mathrm{cw}}{ }^{j}\right)}{\delta \lambda_{a}} .
\end{aligned}
$$

The second problem is:

$$
\begin{aligned}
& 0,5 \beta_{2} t_{1} t_{i_{1}, i_{2}-1}^{j+1}-k_{2} t_{1}{ }_{i_{1}, i_{2}}^{j+1}+0,5 \beta_{2} t_{1 i_{1}, i_{2}+1}^{j+1}=-F_{i_{1}, i_{2}}^{j+1}, i_{2}=1,2, \ldots, N_{2}-1\left(0<i_{1}<N_{1}\right), \\
& \beta_{1}=\frac{\lambda_{a} \Delta \tau}{C_{a}\left(h_{1}\right)^{2}}, \beta_{2}=\frac{\lambda_{a} \Delta \tau}{C_{a}\left(h_{2}\right)^{2}}, k_{2}=1+\beta_{2}-\frac{\Delta \tau}{2 \delta c_{a}}\left(\alpha_{1}+\frac{\lambda_{u 3}}{h_{3}}\right), \\
& F_{i_{1}, i_{2}}^{j+1}=0,5 \beta_{1}\left(t_{1 i_{1}-1, i_{2}}^{j+1 / 2}+t_{1} t_{i_{1}+1, i_{2}}^{j+1 / 2}\right)+\left(1-\beta_{1}\right) t_{1 i_{1}, i_{2}}^{j+1 / 2}-\frac{\lambda_{a} \Delta \tau}{2 c_{a}} f^{j+1 / 2}, \\
& f^{j+1 / 2}=\left(\frac{\lambda_{u 3}}{\lambda_{a} \delta h_{3}} t_{u i_{1}, i_{2}}^{j}+\frac{\alpha_{1}}{\lambda_{a} \delta} t_{w}(\Delta \tau(j+0,5)) .\right.
\end{aligned}
$$

The boundary conditions are: 


$$
\begin{aligned}
& t_{1 i_{1}, 0}^{j+1}=t_{1 i_{1}, 0}^{j+1}+\mathrm{h}_{2}\left(\frac{\left(t_{1 i_{1,0}}^{j}-t_{2 i_{1,0}}^{j}\right)}{l_{4}}+L\right), \\
& t_{1 i_{1}, N_{2}}^{j+1}=t_{1 i_{1}, N_{2}-1}^{j+1}+h_{2}\left(\frac{\left(t_{2 i_{1}, N_{2}}^{j}-t_{1 i_{1}, N_{2}}^{j}\right)}{l_{3}}+L\right) ;
\end{aligned}
$$

The scheme of alternating directions for the equation of an internal panel skin is derived similarly.

For the insulation layer the differential analog of the equation (10) will have a form:

$$
\frac{\lambda_{s} \Delta \tau}{c_{s}\left(h_{3}\right)^{2}} t_{s i_{1}, i_{2}, i_{3-1}}^{j+1}-\frac{2 \lambda_{s} \Delta \tau}{c_{s}\left(h_{3}\right)^{2}} t_{u 3}^{j+1} \underset{i_{1}, i_{2}, i_{3}}{j+1}+\frac{\lambda_{s} \Delta \tau}{c_{s}\left(h_{3}\right)^{2}} t_{s i_{1}, i_{2}, i_{3+1}}^{j+1}=-t_{s}{ }_{i_{1}, i_{2}, i_{3}}^{j+1}, i_{3}=1,2, \ldots, N_{3}-1
$$

The boundary conditions are

$$
t_{s} i_{i_{1}, i_{2}, 0}^{j+1}=t_{1}{ }_{i_{1}, i_{2}}^{j}, t_{s} t_{i_{1}, i_{2}, N_{3}}^{j+1}=t_{2}{ }_{i_{1}, i_{2}}^{j}
$$

The received systems allows to use the tridiagonal matrix algorithm to solute them.

The constructed scheme of alternating directions is stable and converges at a speed of

$$
O\left(\sum_{i=1}^{3} h_{i}^{2}+(\Delta \tau)^{2}\right)
$$

To calculate the temperature of infiltrated air, the methodology described in [1] has been used. When computer modelling the temperature field the symmetry was taken into account. All information was stored for a quarter of the fragment and restored due to the symmetry for other sections of the construction. Besides, variable step toward the panel edges was used, for the temperature field at the fragment edges has very strong heterogeneity. On each time step heat rejection ratio of a vertical and horizontal joints surface, the cold air temperature arriving through joints, and calculation of temperature at an internal and external panel skin surface as well as in the insulation layer were defined. To check the calculations accuracy by the proposed method additional calculations were made, the results of which were compared with the calculations results by stationary model, for which there is a comparison with in - situ measurements [1]. The comparison showed almost total agreement between the calculated temperatures. Figure 1 shows the results of the calculated steady temperature fields of the inner and outer surfaces according to [1].

The temperature field calculation by the above method allows to calculate the heat flow through the panels and through the joints and assess their contribution to the overall heat loss at any time.

Heat flow through panels

$$
Q(\tau)=\int_{-(a-\delta)}^{a-\delta} d x \int_{-(b-\delta)}^{b-\delta} \alpha_{1}\left(t_{w}(\tau)-t_{1}(\tau, x, y)\right) d y .
$$

Heat flow through a panel joint $x=a$ :

$\left.Q(\tau)\right|_{x=a}=-\lambda_{a} \cdot \delta \cdot \int_{-b}^{b}\left[\left.\frac{\partial t_{1}(\tau, x, y)}{\partial x}\right|_{x=a}\right] d y$

similarly $x=-a, y= \pm b$. 


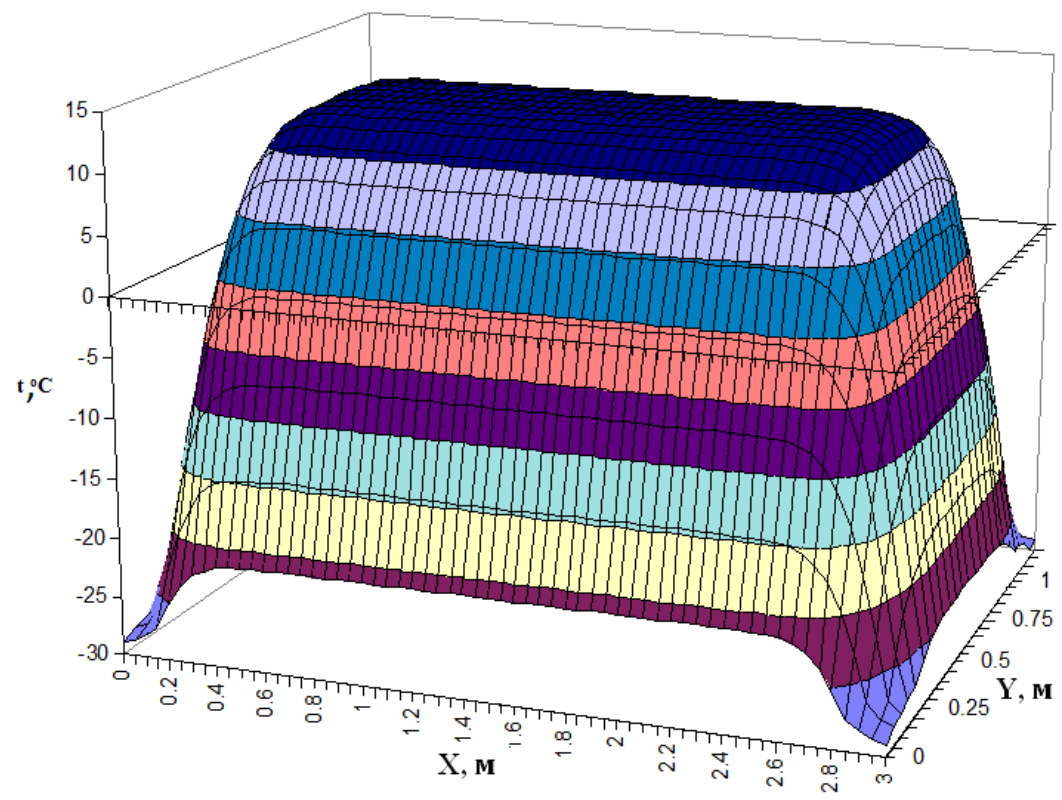

a)

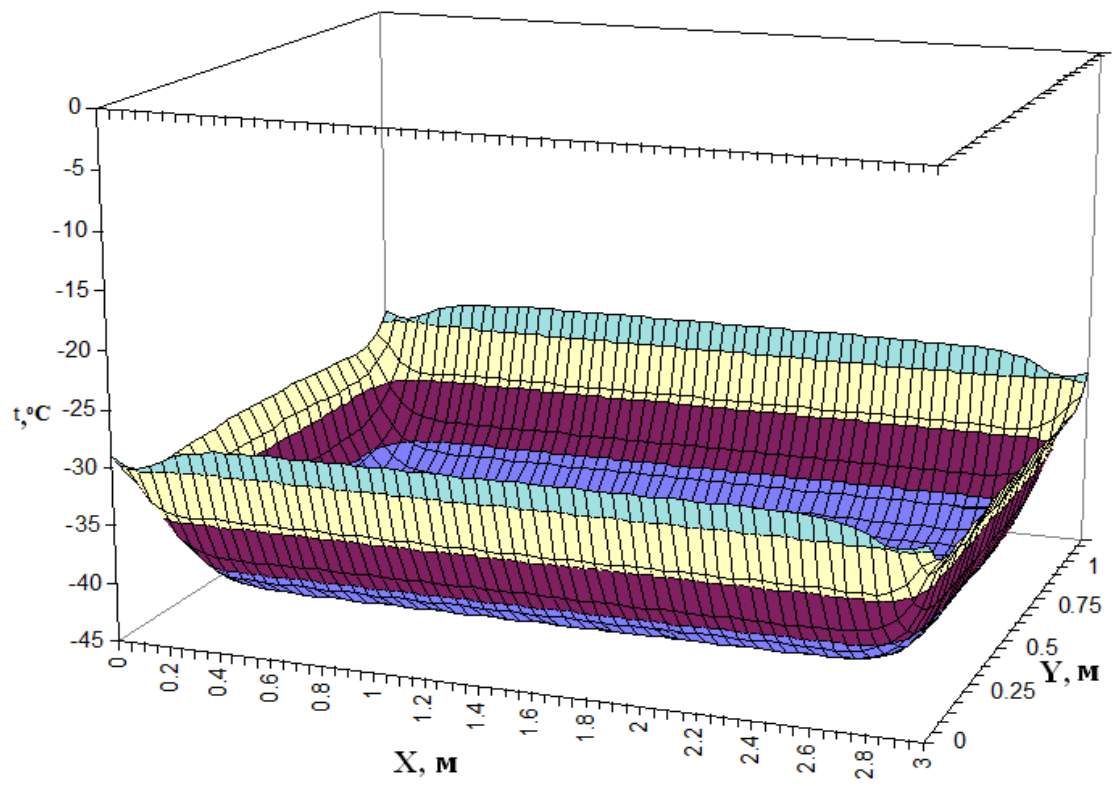

b)

Fig. 1. Temperature field of the panel skin; a) is an internal surface; b) is an external surface. 


\section{Results}

The physical and mathematical model of heat exchange through the enclosure structure is developed. The model considers non-stationarity of the process and heat exchange connected with heat-conducting inclusions and infiltration of air in panel joints.

This model can be rather effective to design a multilayered heat insulation panels as the above calculations have shown that at non-stationary heat exchange process heat loss depends on sequence of layers along cross section.

\section{Conclusion}

When using the enclosure structure it takes from 15 to 20 hours to establish the stationary condition. Thus, the stationary condition practically does not occur. Accurate thermo physical calculation can be made only with the help of the non-stationary model.

In lightweight enclosure structure up to $75 \%$ of heat loss falls on the joints between panels. And about $30 \%$ is lost through infiltration and $45 \%$ through the joints formed in "thermal bridge". To reduce heat loss through the enclosure structure it is more efficient to seal joints and destroy "thermal bridge" but not increase the panel thickness or use a better thermal insulator.

\section{References}

1. V.V. Remizov, A.F. Shapoval, B.V. Moiseev, B.G. Aksenov, Osobennosti stroitel'stva ob'ektov v neftegazodobyvajushhih rajonah Zapadnoj Sibiri (Nedra, Moscow, 1996)

2. A.N. Tihonov, A.A. Samarskij, Uravnenija matematicheskoj fiziki (Nauka, Moscow, 1977)

3. S.Ya. Kushnir, A.I. Gorkovenko, A.S. Gorelov, Soil Mechanics and Foundation Engineering, 42(4), 147-151 (2005)

4. G.V. Kuznetsov, M.A. Sheremet, Izv. RAN. Mehanika zhidkosti i gaza, 6, 29-39 (2006)

5. V.N. Bogoslovskij, Teplovoj rezhim zdanija (Strojizdat, Moscow, 1979)

6. E.G. Maljavina, Teplopoteri zdanija (AVOK - PRESS, Moscow, 2007)

7. L. Banhidi, Teplovoj mikroklimat pomeshhenij (Strojizdat, Moscow, 1981)

8. V.N. Bogoslovskij, Stroitel'naja teplofizika (Vysshaja shkola, Moscow, 1982)

9. L.D. Boguslavskij, Snizhenie rashoda jenergii pri rabote sistem otoplenija, ventiljacii $i$ kondicionirovanija vozduha (Strojizdat, Moskva, 1982)

10. E.A. Nasonov, Sb. nauchny trudov NIIST, 161-169 (1966)

11. SP 60.13330.2012 SanPiN 2.2.4.548 - 96

12. SNiP 23-02-2003.

13. Tri «Je», ESCO Jelektronnyj zhurnal jenergoservisnoj kompanii «Jekologicheskie sistemy», 1, (2007)

14. Ju.A. Surinov, Izvestija vuzov. Chernaja metallurgija, 58-66 (1997)

15. A.N. Skanavi, Konstruirovanie i raschet vodjanogo i vozdushnogo otoplenija zdanij (Strojizdat, Moscow, 1983)

16. S.N. Shorin, Teploperedacha. V sbornike: Sovremennye voprosy otoplenija i ventiljacii, (1949)

17. Ju.A. Tabunshhikov, Raschety temperaturnogo rezhima pomeshhenija i trebuemoj moshhnosti dlja ego otoplenija ili ohlazhdenija (Strojizdat, Moscow, 1981)

18. S.A. Krupennikov, Izv. vuzov, Chernaja metallurgija, 5, 46-49 (1995)

19. T.A. Nagornova, Vserossijskaja nauchno-prakticheskaja konferencija s mezhdunarodnym uchastiem «Fedorovskie chtenija», 165-166 (2013) 
20. G.Ja. Mamontov, T.A. Nagornova, N.I. Kurilenko, V.I. Maksimov, Izvestija Tomskogo politihnicheskogo universiteta, 323(4), 66-70 (2013) 